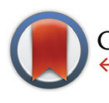

CrossMark \&lick for updates

Cite this: Org. Biomol. Chem., 2014, 12, 9180

Received 1st August 2014, Accepted 29th September 2014

DOI: 10.1039/c4ob02056a

www.rsc.org/obc

\section{Carbohydrate-based N-heterocyclic carbenes for enantioselective catalysis $\uparrow$}

\author{
Alexander S. Henderson, John F. Bower* and M. Carmen Galan*
}

Versatile syntheses of $\mathrm{C} 2$-linked and $C_{2}$-symmetric carbohydrate-based imidazol(in)ium salts from functionalised amino-carbohydrate derivatives are reported. The novel $\mathrm{NHCs}$ were ligated to $[\mathrm{Rh}(\mathrm{COD}) \mathrm{Cl}]_{2}$ and evaluated in Rh-catalysed asymmetric hydrosilylation of ketones with good yields and promising enantioselectivities.
$\mathrm{N}$-heterocyclic carbenes (NHCs) have been extensively exploited over the last few decades as ligands in transition-metal catalysis. ${ }^{1,2}$ However, the use of chiral NHCs in enantioselective catalysis remains underdeveloped. ${ }^{2}$ A key challenge resides in the development of systems that are able to relay efficiently ligand chirality to the coordination sphere of the metal centre. Most efforts in this area have been devoted to modification of the NHC backbone or the use of chiral motifs (e.g. functionalised arenes, amino acids) as N-substituents. ${ }^{1-3}$ Complementary methodologies that enable the incorporation of cheap and diversifiable chiral building blocks onto NHC scaffolds will likely accelerate the development of efficient ligand systems. ${ }^{1 d}$

Carbohydrates are one of the most diverse and important classes of biomolecule. Nature provides in carbohydrates a toolkit of well-defined chirality that is primed for modification. It is not surprising then, that carbohydrate scaffolds have been employed successfully as ligands for enantioselective transition-metal catalysis. ${ }^{2,4}$ Within this area, the design of NHCbased systems has received relatively little attention (Fig. 1A). ${ }^{5}$ Anomeric reactivity has been exploited to append the NHC unit (via nitrogen) to $\mathrm{C} 1$ of the carbohydrate. ${ }^{5 a, c, d, f, g}$ Related C3- and C6-linked monosaccharide systems have also been disclosed. ${ }^{5 b, e, h}$ In most cases, application to enantioselective transition-metal catalysis has not been pursued. ${ }^{5 a-c, e-g}$ A C1-linked carbohydrate-functionalized Ru catalyst was evaluated in asymmetric ring-opening cross-metathesis (AROCM) but high yields could only be achieved with modest enantioselectivities (up to 26 ee). ${ }^{5 d}$ More recently, elegant work by Sollogoub and coworkers has demonstrated that C6-linked NHC-capped cyclodextrins provide chiral "cavities" that mediate enantioselective gold-catalysed alkene cyclopropanation in up to $59 \%$ ee. ${ }^{5 h}$

School of Chemistry, University of Bristol, Cantock's Close, Bristol BS8 1TS, UK. E-mail: john.bower@bris.ac.uk,m.c.galan@bris.ac.uk

$\dagger$ Electronic supplementary information (ESI) available: Experimental procedures and data, NMR spectra and X-ray data for 12c. CCDC 1017544. For ESI and crystallographic data in CIF or other electronic format see DOI: 10.1039/c4ob02056a
(A) Carbohydrate NHCs in Enantioselective Catalysis (Previous Approaches):

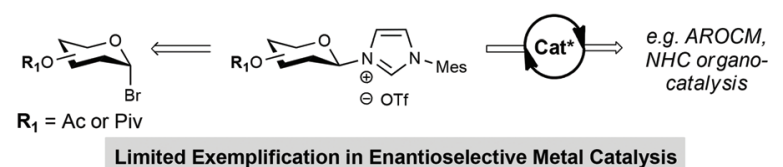

(B) $\mathrm{C}_{2}$-Symmetric NHCs from 2-Amino-Sugars (This Work):

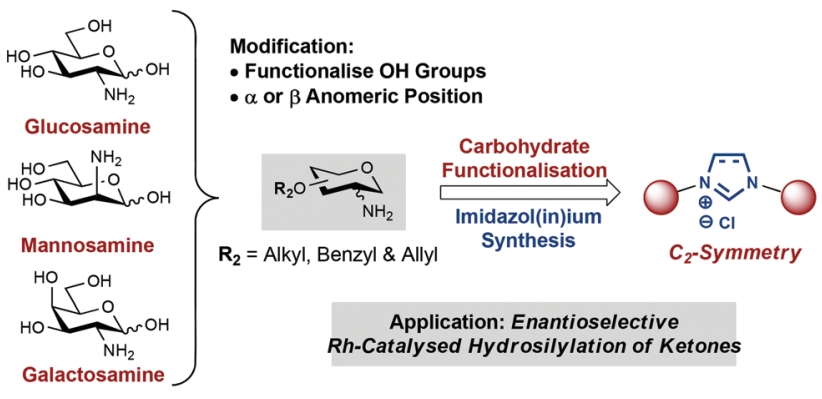

Fig. 1 Carbohydrate NHCs in asymmetric catalysis.

Nevertheless, applications of carbohydrate-based NHCs to enantioselective transition-metal catalysis remain underexplored. ${ }^{5 d}$

As part of our ongoing interest in imidazolium-linked sugar building blocks for oligosaccharide synthesis, ${ }^{6}$ we became interested in their application as carbene ligands for catalysis. Herein we report flexible synthetic entries to a series of C2linked and $C_{2}$-symmetric carbohydrate-based NHCs (Fig. 1B). As a proof of concept, we demonstrate the complexation of these to afford a series of neutral $\mathrm{Rh}(\mathrm{I})$ catalysts, that show promising activity for enantioselective ketone hydrosilylation.

Previous reports have linked carbohydrates to the imidazolium core via the $\mathrm{C} 1, \mathrm{C} 3$ or $\mathrm{C} 6$ positions. ${ }^{5}$ To prepare moderately rigid NHC complexes that might allow the chirality of the glycan to be propagated to the substrate during catalysis, attachment via C6 was deemed as suboptimal. Anomeric (C1) attachment was also discounted to avoid problems associated with diastereocontrol at this centre and the stability of the 

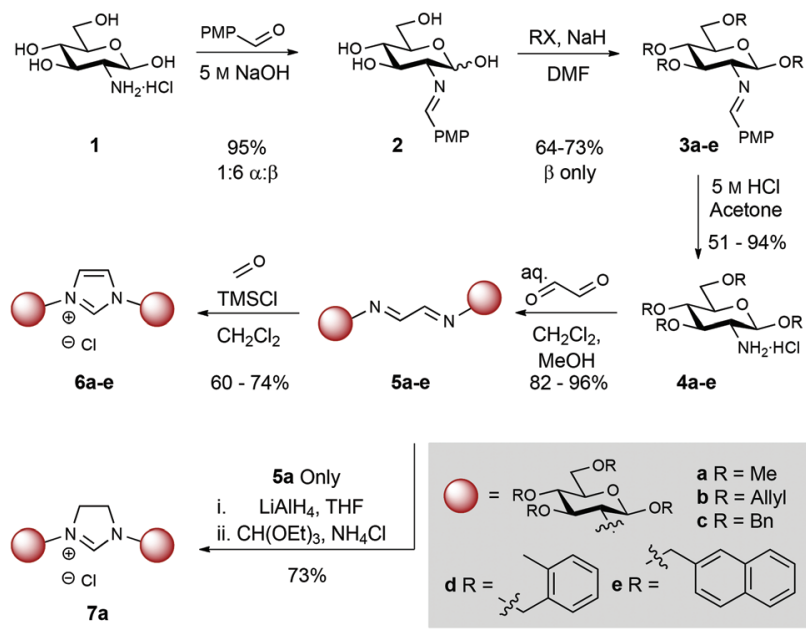

Scheme 1 Synthesis of $\beta$-glucosamine based $\mathrm{NHC} \cdot \mathrm{HCl}$ salts.

eventual NHC. Therefore, and given the availability of C2 amino-carbohydrates, we have targeted a series C2-linked imidazol(in)ium salts (Fig. 1B).

Commercially available D-glucosamine hydrochloride, which bears an equatorial amine at $\mathrm{C} 2$, was initially chosen for this study (Scheme 1). Treatment of amine 1 with $p$-anisaldehyde under basic conditions provided imine 2 in $95 \%$ yield (1:6 $\alpha: \beta$ mixture). Alkylation of the remaining hydroxyl groups with either methyl iodide, allyl bromide, benzyl bromide, 1-(bromomethyl)-2-methylbenzene, or 2-(bromomethyl)naphthalene in the presence of $\mathrm{NaH}$ gave compounds $3 a-e$ in $64-73 \%$ yield. Imine hydrolysis (5 $\mathrm{M} \mathrm{HCl})$ afforded differentially protected amino building blocks 4a-e (51-94\% yield). Bidirectional condensation with glyoxal then generated bis-iminoethylidene derivatives 5 a-e in $82-96 \%$ yield. Ringclosure to the corresponding imidazolium chlorides $\mathbf{6 a - e}$ was achieved in $60-74 \%$ yield using TMSCl and paraformaldehyde. ${ }^{7}{ }^{1} \mathrm{H}$ NMR data unambiguously confirmed the formation of the $\mathrm{C} 2$ derived glucoside-imidazolium structures (singlet at $\delta: 12.31-11.96 \mathrm{ppm}$ corresponding to the $\mathrm{C} 2 \mathrm{H}$ imidazolium, and carbohydrate anomeric signals $\left(\mathrm{d}, J_{1,2}=8.0-8.5 \mathrm{~Hz}\right.$ at $\delta: 6.40-5.52 \mathrm{ppm}$ ). Additionally, glucosamine derived imidazolinium $7 \mathbf{a}$ was prepared by reduction of $5 \mathbf{a}$ to the corresponding diamine $\left(\mathrm{LiAlH}_{4}\right)$, and subsequent condensation with triethyl orthoformate. This allowed access to a comparable imidazolinium ligand.

To study the effects of sugar ring substituent configuration (C2 axial vs. equatorial) on overall catalytic efficiency and selectivity, mannosamine scaffolds were also targeted (Scheme 2). Azido-containing mannopyranoside $\mathbf{8},{ }^{8}$ which can be prepared in 3 steps from commercial 1-O-methyl- $\alpha$-D-mannopyranoside, was subjected to acetal hydrolysis $(\mathrm{TsOH})$, followed by permethylation with methyl iodide and $\mathrm{NaH}$. Subsequent Pd-catalysed hydrogenation of the azide furnished amine 9 in $89 \%$ yield over 3 steps.

Attempts to condense $\mathbf{9}$ following the same conditions as described for the glucose series (Scheme 1), proceeded with low efficiency, probably due to decreased reactivity and steric

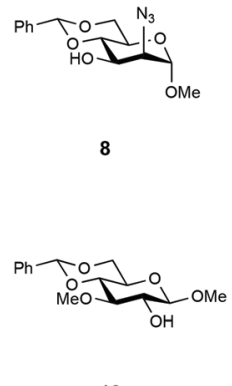

10

$89 \%$

i. $\mathrm{Tf}_{2} \mathrm{O}, \mathrm{Pyr}$

ii. $\mathrm{NaN}_{3}, \mathrm{DMF}$

iii. TsOH. $\mathrm{H}_{2} \mathrm{O}$

iv. $\mathrm{Mel}, \mathrm{NaH}$

Pd/

$6 \%$

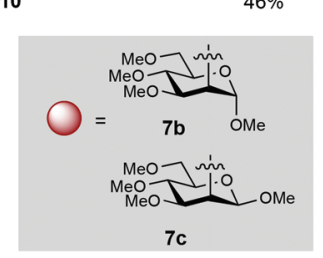

i. $\mathrm{TsOH} \cdot \mathrm{H}_{2} \mathrm{O}$

iii. $\mathrm{Pd} / \mathrm{C}, \mathrm{H}_{2}$

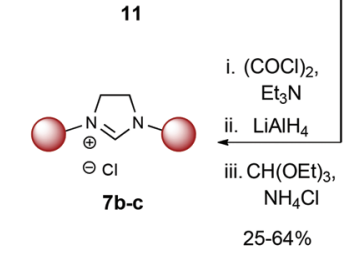

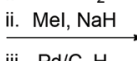

Scheme 2 Synthesis of mannosamine based $\mathrm{NHC} \cdot \mathrm{HCl}$ salts.

hindrance of the axial amine (vs. equatorial amine as in 4a-e). ${ }^{9}$ Consequently, we elected to explore conversion to the corresponding imidazolinium salts. To this end, mannosamine derivative 9 was reacted with oxalyl chloride to yield the corresponding bis-amide. Carbonyl reduction with $\mathrm{LiAlH}_{4}$ followed by thermal condensation/cyclization with $\mathrm{CH}(\mathrm{OEt})_{3}$ in the presence of $\mathrm{NH}_{4} \mathrm{Cl}$ afforded imidazolinium $\mathbf{7 b}$.

$\beta$-D-Mannosamine $\mathbf{1 1}$ was obtained from known $\beta$-D-glucoside 10 (Scheme 2), ${ }^{10}$ which is accessible from commercial 1,2:5,6-di-O-isopropylidene- $\alpha$-D-glucofuranose (see $\mathrm{ESI}^{\dagger} \dagger$ for details). Triflation of the $\mathrm{C} 2 \mathrm{OH}$ was followed by displacement with azide $\left(\mathrm{NaN}_{3}\right)$ to install the synthetically challenging $\beta$-Dmannosamine scaffold. Sequential acetal hydrolysis, permethylation and azide reduction then afforded amine 11 in a $46 \%$ over 5 steps. In an identical fashion to $\mathbf{9}$, the imidazolinium moiety was constructed by formation of bis-amide, reduction to the secondary amine and then thermal cyclisation with $\mathrm{HC}(\mathrm{OEt})_{3}$ and $\mathrm{NH}_{4} \mathrm{Cl} .{ }^{1} \mathrm{H}$ NMR data confirmed the formation of the glycan-imidazolinium structures (singlet at $\delta$ : 9.96-9.69 ppm corresponding to the $\mathrm{C} 2 \mathrm{H}$ imidazolinium and carbohydrate $(\mathrm{H}-1)$ signals $\left(\mathrm{d}, J_{1,2}=1.5(7 \mathbf{b})\right.$ and $\left.2.0(7 \mathrm{c}) \mathrm{Hz}\right)$ at $\delta: 5.12(7 \mathbf{b})$ and $4.47(7 \mathrm{c}) \mathrm{ppm})$.

To demonstrate utility, ligation of the carbenes derived from imidazol(in)iums $\mathbf{6 a - e}$ and $7 \mathbf{a}-\mathbf{c}$ to $\mathrm{Rh}(\mathrm{I})$ was pursued. Pleasingly, base-promoted complexation ( $\mathrm{NaO} t-\mathrm{Bu}$ or $\mathrm{KO} t-\mathrm{Bu}$ ) to $[\mathrm{Rh}(\mathrm{COD}) \mathrm{Cl}]_{2}$ proceeded smoothly and the target Rh-NHCs 12a-e and 13a-c were isolated in moderate to good yield. These complexes were purified by flash column chromatography and show good stability in the solid state (Scheme 3$)^{11}$ Complex 12c was characterized by X-ray diffraction (Scheme 3A) and this revealed an $\mathrm{N}-\mathrm{C}-\mathrm{N}$ angle of $103.2^{\circ}$ and a $\mathrm{C}-\mathrm{Rh}$ bond length of $2.03 \AA$; these values are in line with other reported Rh-NHC complexes. ${ }^{12}$

As a benchmark reaction, we investigated the application of [Rh(NHC)]-based catalysts $\mathbf{1 2 - 1 3}$ to enantioselective ketone hydrosilylation, a process that is sensitive to the electronic and steric demands of the substrate. ${ }^{13}$ Complex 12a catalysed the 

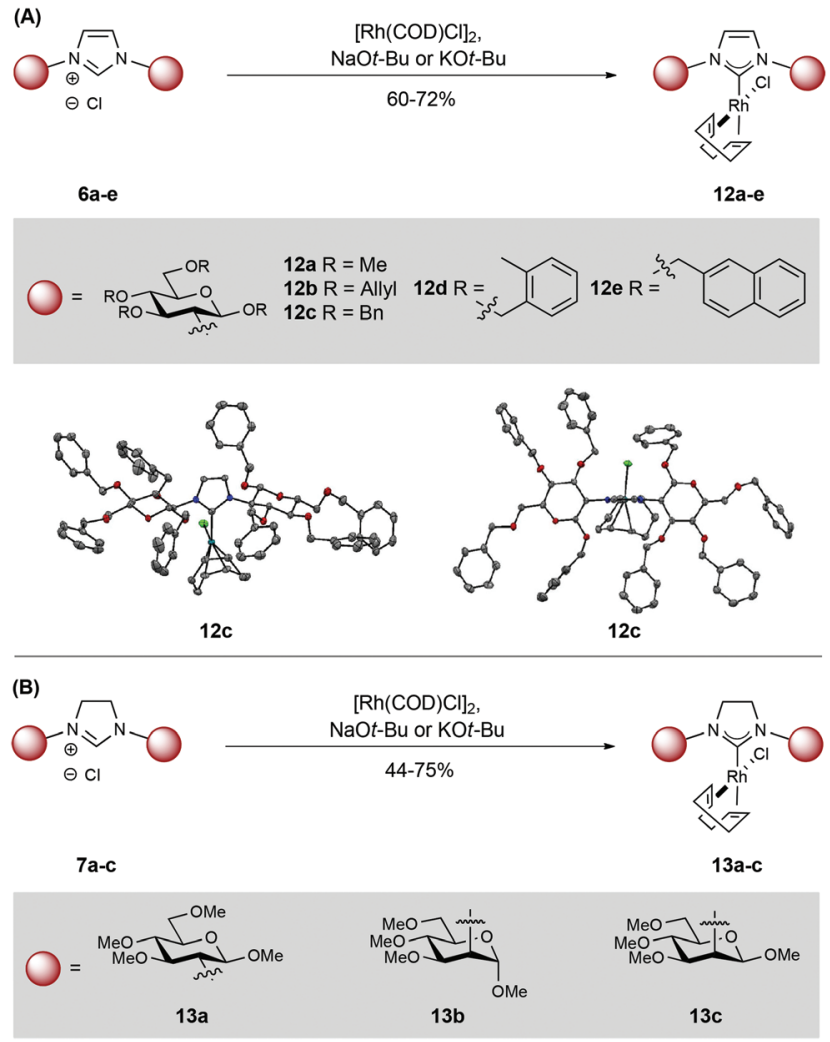

Scheme 3 Complexation of $\mathrm{NHC}$ ligands to $[\mathrm{Rh}(\mathrm{COD}) \mathrm{Cl}]_{2}$.

1,2-additon of diphenylsilane to acetophenone $\mathbf{1 4 a ^ { 1 4 }}$ and, following acid promoted $(\mathrm{HCl})$ cleavage of the silyl ether, alcohol 15a was isolated in 62\% yield and 80:20 er (Table 1, entry 1). Hydrolysis under basic conditions $\left(\mathrm{K}_{2} \mathrm{CO}_{3}, \mathrm{MeOH}\right)$ provided an increased yield of 15a but no change in er (entry 2$).{ }^{15}$ Complex 13a, which is the imidazolinium analogue of $12 \mathbf{a}$, provided similar levels of enantioselectivity $(80: 20 R: S$ ), (entry 3 ). Allylated and benzylated complexes $\mathbf{1 2 b}-\mathbf{e}$, which possess bulkier modifying groups on the carbohydrate unit compared to 12a,

Table 1 Initial screen of carbohydrate-NHC complexes in Rh-catalysed hydrosilylation of acetophenone

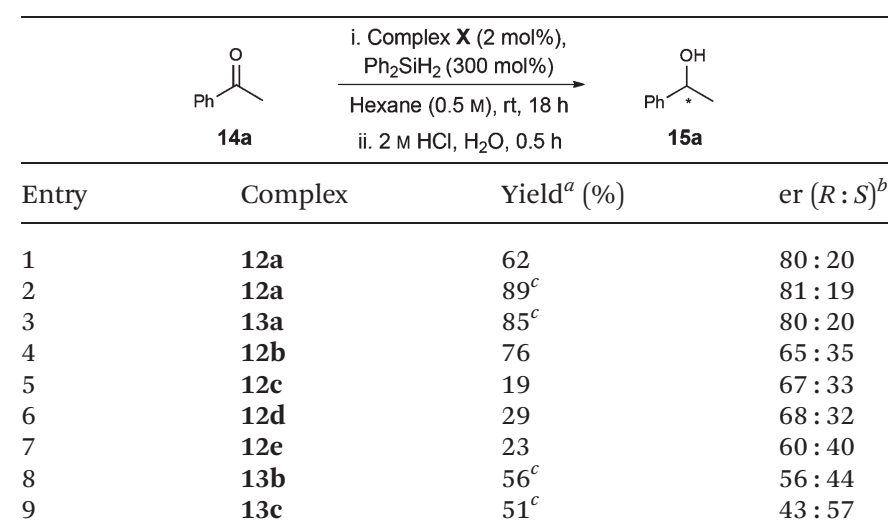

${ }^{a}$ Isolated yields. ${ }^{b} R: S$ ratios were determined by chiral HPLC using the corresponding racemate as a standard. ${ }^{c}$ Optimised silyl ether cleavage conditions: $\mathrm{K}_{2} \mathrm{CO}_{3}, \mathrm{MeOH}, 2 \mathrm{~h}$.

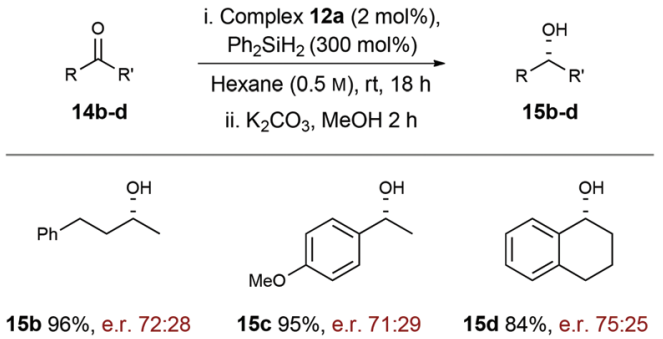

Scheme 4 Exploration of ketone scope with complex 12a.

gave lower levels of enantiocontrol (entries 5-7). ${ }^{16}$ Changing the configuration of the $\mathrm{C} 2$ amine in the glycan from equatorial (glucos-) to axial (mannos-) (13b/c) had a detrimental effect in both yield and enantioselectivity (entries 9 and 10). Interestingly, a switch in preference from $R$ to $S$ was observed for the formation of 15a when changing from an $\alpha$ to a $\beta$ configuration at $\mathrm{C} 1(\mathbf{1 3 b}$ vs. 13c). These results highlight the importance of substituent configuration and size on the carbohydrate scaffold and show that these factors can affect the enantioselectivity of the reaction.

To explore scope further, hydrosilylation of structurally diverse ketones 14b-d was explored using complex 12a (Scheme 4). Pleasingly, reaction yields were uniformly high (84-96\% yield) and the products were formed with similar levels of enantioselectivity $(71: 29-75: 25 ; R: S)$ across the range of alkyl-alkyl (15b), aryl-alkyl (15c), and bicyclic (15d) ketone motifs. Evidently further optimisation is required, but these results demonstrate that the carbohydrate-based NHC ligand of 12a is effective at relaying chiral information to the "active" coordination sites of the Rh-complex.

In conclusion, we outline flexible routes to a family of novel C2-linked and $C_{2}$-symmetric carbohydrate-based NHCs. Suitable selection and modification of the carbohydrate unit is readily achieved and this provides "tunable" access to a diverse range of derivatives. The corresponding $\mathrm{Rh}(\mathrm{I})$-complexes are accessed easily and display promising enantioselectivities in ketone hydrosilylation. Overall, the results described here highlight the potential of this family of simple and modifiable carbohydrate derived NHCs as ligands for enantioselective transition metal catalysis. The development and application of related classes of chiral NHC will be reported in due course.

\section{Acknowledgements}

We thank the EPSRC Bristol Chemical Synthesis CDT (ASH), EPSRC (EP/J007455/1) and the Royal Society (JFB) and the EPSRC (EP/J002542/1 and EP/L001926/1) (MCG). Dr M. Haddow (University of Bristol) is thanked for XRDS of 12c.

\section{Notes and references}

1 (a) W. A. Herrmann and C. Köcher, Angew. Chem., Int. Ed. Engl., 1997, 36, 2162; (b) S. Díez-González, N. Marion and 
S. P. Nolan, Chem. Rev., 2009, 109, 3612; (c) L. A. Schaper, S. J. Hock, W. A. Herrmann and F. E. Kühn, Angew. Chem., Int. Ed., 2013, 52, 270; (d) L. Benhamou, E. Chardon, G. Lavigne, S. Bellemin-Laponnaz and V. César, Chem. Rev., 2011, 111, 2705.

2 (a) V. César, S. Bellemin-Laponnaz and L. H. Gade, Chem. Soc. Rev., 2004, 33, 619; (b) F. Wang, L. J. Liu, W. Wang, S. Li and M. Shi, Coord. Chem. Rev., 2012, 256, 804.

3 (a) A. Schumacher, M. Bernasconi and A. Pfaltz, Angew. Chem., Int. Ed., 2013, 52, 7422; (b) A. Monney and M. Albrecht, Coord. Chem. Rev., 2013, 257, 2420; (c) F. Glorius, G. Altenhoff, R. Goddard and C. Lehmann, Chem. Commun., 2002, 2704; (d) D. M. Lindsay and D. McArthur, Chem. Commun., 2010, 46, 2474; (e) Y. Zhao and S. R. Gilbertson, Org. Lett., 2014, 16, 1033; (f) K. C. Nicolaou and H. J. Mitchell, Angew. Chem., Int. Ed., 2001, 40, 1576.

4 (a) M. M. K. Boysen, Chem. - Eur. J., 2007, 13, 8648; (b) S. Castillón, C. Claver and Y. Díaz, Chem. Soc. Rev., 2005, 34, 702; (c) M. Diéguez, O. Pàmies and C. Claver, Chem. Rev., 2004, 104, 3189; (d) B. Gyurcsik and L. Nagy, Coord. Chem. Rev., 2000, 203, 81; (e) D. Steinborn and H. Junicke, Chem. Rev., 2000, 100, 4283.

5 (a) F. Tewes, A. Schlecker, K. Harms and F. Glorius, J. Organomet. Chem., 2007, 692, 4593; (b) J. C. Shi, N. Lei, Q. Tong, Y. Peng, J. Wei and L. Jia, Eur. J. Inorg. Chem., 2007, 2221; (c) T. Nishioka, T. Shibata and I. Kinoshita, Organometallics, 2007, 26, 1126; (d) B. K. Keitz and R. H. Grubbs, Organometallics, 2010, 29, 403; (e) C. C. Yang, P. S. Lin, F. C. Liu and I. J. B. Lin, Organometallics, 2010, 29, 5959; $(f)$ T. Shibata, H. Hashimoto, I. Kinoshita, S. Yano and T. Nishioka, Dalton Trans., 2011, 40, 4826; (g) T. Shibata, S. Ito, M. Doe, R. Tanaka, H. Hashimoto, I. Kinoshita, S. Yano and T. Nishioka, Dalton Trans., 2011, 40, 6778; (h) M. Guitet, P. Zhang, F. Marcelo, C. Tugny, J. Jimnez-Barbero, O. Buriez, C. Amatore, V. MourièsMansuy, J. P. Goddard, L. Fensterbank, Y. Zhang, S. Roland, M. Ménand and M. Sollogoub, Angew. Chem., Int. Ed., 2013, 52, 7213.

6 (a) M. C. Galan, A. T. Tran and C. Bernard, Chem. Commun., 2010, 46, 8968; (b) A. T. Tran, R. Burden, D. T. Racys and M. C. Galan, Chem. Commun., 2011, 47,
4526; (c) M. C. Galan, A. T. Tran, K. Bromfield, S. Rabbani and B. Ernst, Org. Biomol. Chem., 2012, 10, 7091; (d) M. C. Galan, R. A. Jones and A. T. Tran, Carbohydr. Res., 2013, 375, 35.

7 L. Hintermann, Beilstein J. Org. Chem., 2007, 3, 22.

8 A. Popelová, K. Kefurt, M. Hlaváčková and J. Moravcová, Carbohydr. Res., 2005, 340, 161.

9 A. Burkhardt, H. Görls and W. Plass, Carbohydr. Res., 2008, 343, 1266.

10 C. M. Nycholat and D. R. Bundle, Carbohydr. Res., 2009, 344, 1397.

11 The Rh(I)-complexes described here were stored under air and no deterioration in catalytic activity was observed over 6 months.

12 (a) P. A. Evans, E. W. Baum, A. N. Fazal and M. Pink, Chem. Commun., 2005, 63; (b) W. Duan, Y. Ma, F. He, L. Zhao, J. Chen and C. Song, Tetrahedron: Asymmetry, 2013, 24, 241.

13 (a) Review: K. Riener, M. P. Högerl, P. Gigler and F. E. Kühn, ACS Catal., 2012, 2, 613; (b) Mechanistic study: N. Schneider, M. Finger, C. Haferkemper, S. BelleminLaponnaz, P. Hofmann and L. H. Gade, Angew. Chem., Int. Ed., 2009, 48, 1609; (c) W. L. Duan, M. Shi and G. B. Rong, Chem. Commun., 2003, 2916; (d) L. H. Gade, V. César and S. Bellemin-Laponnaz, Angew. Chem., Int. Ed., 2004, 43, 1014; (e) A. Albright and R. E. Gawley, J. Am. Chem. Soc., 2011, 133, 19680.

14 The use of hexane as solvent led to greatest levels of asymmetric induction for the reduction of 14a to 15a. See ESI $\dagger$ for further catalytic data with the use of other common solvents.

$15{ }^{1} \mathrm{H}$ NMR of crude material (Table 1, entry 1) showed full conversion of 14a to a mixture of silylated alcohol ( 90\%) and silyl enol ether byproduct ( $\sim 10 \%)$. De-silylation using aq. $\mathrm{HCl}$ was inefficient, while the use of $\mathrm{K}_{2} \mathrm{CO}_{3}$ in $\mathrm{MeOH}$ allowed the isolation of 15a in a yield that reflects the efficiency of the reduction step.

16 During catalytic runs with 12c-e (entries 4-6), catalyst precipitation was noted. HRMS of these precipitates was consistent with partial O-debenzylation occurring. We postulate the reductive cleavage of the benzyl ethers and concomitant formation of the alcohol, results in a less soluble catalyst and/or leads to deactivation. 